\title{
CONTRIBUIÇÃO À ANÁLISE E ESTRUTURAÇÃO DAS DEMONSTRAÇÕES FINANCEIRAS DAS SOCIEDADES COOPERATIVAS BRASILEIRAS
}

\author{
Anisio Candido Pereira \\ Doutor em Ciências Contábeis pela FEA/USP
}

\section{- Ensaio de Abordagem Social - 1) Introdução}

É freqüente a afirmação de que existem, basicamente, duas classificações de entidades: as que visam essencialmente à obtenção de lucro, e as que buscam predominantemente objetivos sociais.

No primeiro caso, há uma forma relativamente simplificada de se avaliar o desempenho das entidades e também de seus administradores, em relação à consecução de seus fins lucrativos. Basta, por exemplo, comparar os resultados obtidos com os recursos aplicados. Quanto maior for o lucro alcançado em suas operações, melhor será a performance da entidade e também de seus dirigentes.

No segundo caso, torna-se muito mais difícil e complexo avaliar o desempenho das entidades cujos objetivos predominantes são os sociais. O resultado econômico-financeiro não representa a base de avaliação. Trata-se, principalmente, de mensurar o progresso da entidade relativamente aos objetivos sociais não só em termos quantitativos, mas também em termos qualitativos.

Observamos através de nossa pesquisa que, em nosso país, tanto no campo teórico como prático, a ênfase dada na contabilidade das sociedades cooperativas é sobre o aspecto econômico-financeiro, seguindo muito de perto as tendências das empresas capitalistas.

Este trabalho é uma tentativa de sugerir mecanismo de controle pela contabilidade das sociedades cooperativas, de tal forma que possibilite enfatizar o resultado de seus aspectos sociais através de Demonstrações Financeiras para que reflitam a verdadeira posição do Movimento Cooperativista Brasileiro.

\section{2) Conceitos e Definições de Cooperação, Cooperativa e Cooperativismo}

Segundo Baldus e Willens, citados por Diva PINHO (1966, p.7), do ponto de vista sociológico, "Cooperação é uma forma de integração social e pode ser entendida como ação conjugada em que pessoas se unem, de modo formal ou informal, para alcançar o mesmo objetivo".

A Cooperação supõe necessariamente a liberdade de trabalhar em comunidade. Assim, a cooperação possui duas condições importantes e imprescindíveis: liberdade e comunidade, trabalho livre e grupal

Quando organizada segundo estatutos previamente estabelecidos, a cooperação dá origens ás cooperativas.

De uma forma simplificada, pode-se definir cooperativa como sendo uma sociedade de pessoas, constituída em bases democráticas com características empresariais, tendo legislação finalidades específicas para solução de problemas ecônomos e sociais a todos membros associados, com extensão aos seus funcionários e à própria comunidade.

O cooperativismo baseia-se no trabalho e não no lucro, É uma filosofia do homem na sociedade em que vive, baseada na ajuda mútua. Considera os valores e aspirações e não o capital individual acumulado

Cooperação, cooperativa e cooperativismo são palavras que contém cada um o seu próprio significado, embora todas derivem de uma mesma palavra primitiva "cooperar"

\section{3) Desenvolvimento Histórico do Cooperativismo}

Caderno de Estudos nº10, São Paulo, FIPECAFI, Maio/1994 


\section{1) Antecedentes Históricos}

As raízes do Cooperativismo podem ser encontradas na mais remota Antigüidade. De fato, entre os babilônios havia certa forma de arrendamento de terras para a exploração em comum; os gregos e romanos conheciam sociedades de auxílio-mútuo para enterros e seguros etc. Chega-se mesmo a afirmar que os primeiros cristãos esboçaram os rudimentos das cooperativas de consumo ao escolher um grupo de pessoas encarregadas do provisionamento de gêneros alimentícios, destinados ao consumo comum. Também os monastérios medievais, efetuando em comum a produção e o consumo, são interpretados como cooperativas integrais por alguns estudiosos. Outros vêem nas cooperações de ofícios e nas sociedades de auxílio da Idade Média, esquemas elementares de cooperativas.

Quando em seu apogeu, no desenrolar da luta dos trabalhadores na Inglaterra, por ocasião de grandes convulsões sociais e políticas, com o aparecimento de tantos movimentos, doutrinas e teorias aparentemente chamadas a alterar o mundo dessa época em pouco tempo, surgiram as primeiras manifestações reais e positivas do movimento cooperativista, com a função da Sociedade dos Pioneiros de Rochdale, a 21 de dezembro de 1844.

\section{2) Os pioneiros de Rochdale}

Em 1843, a indústria de flanelas estava em seu apogeu em Rochdale, na Inglaterra. Os tecelões, considerando o bom momento por que passava essa indústria, resolveram solicitar aumento de seus pequenos salários. Os donos das indústrias não concordaram.

Um grupo de tecelões, não tendo podido obter aumento que consideravam justo, resolveu se reunir para encontrar algum meio de melhorar a sua péssima situação econômica.

Após muitas discussões, resolveram criar os seus próprios meios de ação mediante auxílio-mútuo. Defenderam a idéia de abrir um armazém cooperativo de consumo.

Em reuniões posteriores, vinte o oito tecelões elaboraram um projeto desse armazém e as bases da sociedade, que recebeu o nome de "Sociedade dos Probos Pioneiros de Rochdale.

Segundo Palmyos CARNEIRO (1981, p.44), foi em Rochdale, na Inglaterra, na época com 24.421 habitantes, que se organizou, em 21.12 1844, uma cooperativa organizada de admirável capacidade de sobrevivência, não como de um acaso, mas sim em virtude da justeza de seus princípios e dos métodos administrativos nela empregados.

Conforme Diva PINHO (1982, p.32), o programa inicial dos Pioneiros de Rochdale tinha como meta:

“Abrir um armazém para venda de gêneros alimentícios, vestuários etc.

Comprar ou construir casas para os membros que desejam ajudar-se mutuamente a fim de melhorar as condições de sua vida doméstica e social.

Iniciar a fabricação de artigos que a sociedade julgar conveniente para proporcionar trabalho aos membros que estiverem desempregados ou cujos salários sejam insuficientes.

Logo que seja possível, a sociedade promoverá a organização da produção, da distribuição e da educação no seu próprio meio e com seus próprios recursos.

Com o objetivo de promover a sobriedade, abrirá, logo que conveniente, um estabelecimento de temperança."

Esses projetos têm por finalidade a reforma do meio econômico-social e podem ser assim sistematizados:

1 formação de um capital para a emancipação do proletariado, mediante economias realizadas sobre a compra em comum de gêneros alimentícios;

2 construção de casas para fornecer habitações a preço de custo;

3 criação de estabelecimentos industriais e agrícolas, com duplo objetivo: produzir direta e economicamente tudo o que for indispensável às necessidades da classe operária e assegurar trabalho aos operários desempregados ou que recebam baixos salários;

Caderno de Estudos nº10, São Paulo, FIPECAFI, Maio/1994 
4 educação e luta contra o alcoolismo;

5 cooperação integral, isto é, criação paulatina de pequenos núcleos, nos quais a produção e as repartições serão reorganizadas, e a multiplicação desses núcleos através da propaganda e do exemplo.

A doutrina cooperativista adotada no mundo todo tem como referência, ainda hoje, os princípios estabelecidos pelos Pioneiros de Rochdale, em 1844.

\section{3) A Origem do Cooperativismo no Brasil}

De acordo com Minoru TAKAHASHI (1982, pág.6), no Brasil, o Cooperativismo só surgiu no final do século XIX, atribuindo-se o interesse por esse novo tipo de sociedade à situação sócio-econômica criada com a abolição da escravatura.

Por outro lado, outros fatores contribuíram para o surgimento das primeiras cooperativas no Brasil, tais como:

a) na Proclamação da República em fins de 1889, quando se propicia um ambiente mais favorável à liberdades de associação, começaram a surgir as primeiras organizações, efetivamente sociedades cooperativas;

b) a Constituição Republicana de 1891 assegurou a liberdade de associação (art. 72, § 8ํㅜ) e o Estado começou a legislar sobre associativismo rural.

A primeira cooperativa criada no Brasil, conforme indicam vários autores, surgiu no ano de 1891, na cidade de Limeira, Estado de São Paulo, e denominou-se Associação Cooperativa dos Empregados da Companhia Telefônica. Em seguida, fundou-se, em 1894, a Cooperativa Militar de Consumo no Rio de Janeiro, e, em 1895, a Cooperativa do Proletariado Industrial de Camaragibe, no Estado de Pernambuco.

Outras cooperativas surgem, como por exemplo a Cooperativa Internacional da Lapa, criada em 1908, existente até os dias atuais e hoje denominada de Cooperativa de Consumo da Lapa.

As cooperativas agrícolas, de um modo geral, só se desenvolveram mais tarde, destacando-se entre elas as cooperativas vinícolas, as tritícolas, as madeireiras, as de laticínios, de café etc.

Em 1927, surge a Cooperativa Agrícola de Cotia, de grande representatividade no país nos dias atuais, malgrado seus percalços financeiros de 7.993.

Atualmente, conforme o Anuário do Cooperativismo Brasileiro, editado pela Organização das Cooperativas Brasileiras em 1991, é a seguinte a posição das cooperativas no Brasil.

TIPO

\section{Quantidade}

Produção 1.400

Consumo .344

Eletrificação Telef.Rural. .204

Escola/Escolar .112

Trabalho. .528

Habitacional. .136

Crédito. .716

TOTAL 3. 440

\section{4) Doutrina Cooperativista}

Caderno de Estudos nº10, São Paulo, FIPECAFI, Maio/1994 
A Doutrina Cooperativista adotada universalmente é baseada, em sua essência, nos princípios estabelecidos pelos Pioneiros de Rochdale, há quase 150 anos.

Segundo Diva PINHO (1977, pág.3). os 'Princípios de Rochdale' ratificados no Congresso da Aliança Cooperativa Internacional - ACI, realizado em Viena em 1966, são.

1. Adesão Livre.

2. Gestão Democrática.

3. Distribuição das Sobras.

4. Juros Limitados ao Capital.

5. Educação dos cooperados e do público geral.

6. Ativa Cooperação entre Cooperativas.

Os princípios que se aplicam atualmente às diversas modalidades de cooperativismo sofreram algumas adaptações com a finalidade de se manterem dentro das mudanças estruturais, da vida econômica e social, que tem sido necessárias para continuarem em vigor.

\section{5) Legislação Cooperativista Brasileira}

A evolução histórica da Legislação Cooperativista Brasileira, conforme Carlos PINHO et al.(1991, pág.75), pode ser analisada em cinco períodos básicos, a saber:

1. As medidas legais pioneiras.

2. O crescimento com apoio legal e institucional.

3. Crise e reorganização.

4. Renovação legal e estrutural.

5. Desatrelamento da Estado e Autogestão.

Enquanto não for promulgada a nova lei cooperativista pelo Congresso Nacional, objetivando adaptá-la à nova realidade brasileira, para atender às importantes inovações cooperativistas introduzidas pela Constituição de 1988, continua em pleno vigor a Lei 5.764 , de 16.12 .1971 no que não conflitar com os dispositivos constitucionais auto-aplicáveis.

O dispositivo mais importante para o cooperativismo brasileiro, constante da Constituição de 1988, é o inciso XVIII do art. $5^{\circ}$., que assim ficou consubstanciado: "Art, $5^{\circ}$ ", "XVIII - a criação de associações e, na forma da lei, a de cooperativas independem de autorização, sendo vedada a interferência estatal em seu funcionamento." Através desse artigo constitucional, o governo brasileiro deixa de ser paternalista, benevolente ou intervencionista, no sentido de ter como obrigação a tutela e fiscalização das cooperativas. Deixa claro, inclusive, que a constituição de novas cooperativas não depende mais de autorização do Estado e que doravante não sofrerão mais a interferência estatal em seu funcionamento.

Se, por um lado, com as alterações introduzidas na nova Constituição do país o cooperativismo brasileiro conquistou uma maior liberdade, a exemplo do que já ocorre em outros países, por outro lado, isso acarretará fatalmente para uma maior responsabilidade, que agora não terá outro caminho senão partir para a autogestão plena a fim de atingir a sua consolidação e ampliar o seu movimento de uma forma qualitativa e quantitativa em todo país.

\section{6) Demonstrações Financeiras das Sociedades Cooperativas}

A Cooperativa, conforme mencionado no tem 2 é definida de urna forma simplificada como sendo: "uma sociedade de pessoas, constituída em bases democráticas, com características empresariais, tendo legislação e

Caderno de Estudos nº10, São Paulo, FIPECAFI, Maio/1994 
finalidades específicas para soluções dos problemas econômicos e sociais a todos membros associados, com extensão à comunidade".

As operações das sociedades cooperativas abrangem aspectos econômicos tal como verificados em qualquer outra empresa capitalista; entretanto, abrangem também, e principalmente, os aspectos sociais, uma vez que esta pode ser considerada, em nosso entender, como sua principal finalidade, considerando o seu enquadramento no rol das empresas sem fins lucrativos.

Para Samuel PECAR (1981, pág.7). "O cooperativismo é um sistema econômico com conteúdo social."

A própria legislação brasileira, art. $3^{\circ}$. e $4^{\circ}$., da Lei $5764 / 71$, leva-nos a esse raciocínio, quando indica que cooperativa é uma sociedade de pessoas, com forma jurídica de natureza civil, constituída para prestar serviços aos seus associados. Estes ficarão obrigados, reciprocamente, a contribuir com bens ou serviços para o exercício de uma atividade econômica, de proveito comum, sem objetivo de lucro.

O legislador brasileiro deixou bem clara a dupla dimensão de cooperativa em social e econômica, acompanhando desta forma, a conceituação adotada na maioria de outros países, tendo como parâmetro, o posicionamento da Aliança Cooperativa Internacional -ACI.

Entretanto, ao analisarmos essas colocações dentro de um ponto de vista prático, visualizamos que, ao se combinarem os caracteres de associação e de empresa ao mesmo tempo, fatalmente se criará um certo grau de dificuldade aos seus administradores. Se, por um lado, a prioridade for muito acentuada no aspecto "associativo" corre-se o risco de conseqüentemente, surgirem dificuldades de ordem financeira na entidade; se, por outro lado, a ênfase for apenas no aspecto "econômico-financeiro. corre-se o risco de haver um distanciamento dos associados, desviando o importante objetivo social da empresa".

Sem dúvida alguma, o ideal é procurar manter-se um equilíbrio dentro dos enfoques apresentados, que poderão ser observados de tempos em tempos, através de avaliações de desempenho tanto das atividades econômicofinanceiras quanto das atividades sociais.

Observamos, através de nosso estudo, que em vários países apresenta-se a tendência de seus contadores em elaborarem as Demonstrações Financeiras das sociedades cooperativas em modelos muito aproximados ao das empresas capitalistas, cujos objetivos são opostos, ou seja, a participação dos sócios existe única e exclusivamente em função do dividendo esperado, proporcionalmente ao lucro a ser obtido. Observamos também que em tais Demonstrações, tanto no plano teórico, como prático, predomina o aspecto econômicofinanceiro.

Este procedimento tem ocorrido também no Brasil, desde o inicio deste século, conforme pudemos constar na análise das Demonstrações Financeiras das Sociedades Cooperativas, quando comparadas às das empresas capitalistas. Nossa pesquisa abrangeu desde as influências do Decreto-Lei 2627, de 26.09.1940, passando pela Circular 179, de 11.05.1972, do Banco Central do Brasil, até a Lei 6.404, de 15.12.1976 Além disso, examinamos também Demonstrações Financeiras de mais de 100 cooperativas de diversos Estados brasileiros para verificar sua tendência atual.

Uma das razões desses procedimentos, em nosso entender, é que o Contador muitas das vezes, não encontrando respostas dentro da lei cooperativista, procura adaptar-se às leis das sociedades capitalistas; talvez essa seja a principal razão da semelhança das Demonstrações Financeiras das sociedades cooperativas com as das demais sociedades.

Se, por um lado, elas devam acompanhar, em parte, os modelos elaborados pelas sociedades capitalistas, para que possam apresentar as suas posições econômico-financeiras na condição de organizações econômicas que também o são, não devem e não podem de forma alguma deixarem de apresentar, através das Demonstrações Financeiras, o reflexo de suas atividades sociais, considerando ser este também um de seus principais objetivos.

O ponto central de nosso estudo é a sugestão de adaptações aos modelos de Demonstrações Financeiras existentes nas sociedades cooperativas, bem como a proposição de novos modelos, visando a mostrar, além de sua condição econômica, dados que permitam aos seus usuários verificar, em determinado período considerado, as realizações de suas atividades sociais, considerando ser esta, talvez, uma das principais razões de sua existência, na condição de empresa sem fim lucrativo.

Com a finalidade de delimitarmos a extensão de nosso trabalho, estamos considerando, por hipótese, as Demonstrações Financeiras de uma Cooperativa de Vendas em Comum e que a mesma proceda a sua movimentação de produtos somente com associados, caracterizando-se, assim, o verdadeiro sentido do Ato Cooperativo.

Sugerimos, por exemplo, a adaptação do Balanço Patrimonial, que de acordo com nosso ponto de vista seria assim demonstrado: 
Contribuição a Análise e Estruturação das Demonstrações Financeiras das Sociedades 6 Cooperativas Brasileiras

\section{COOPERATIVA AGROPECUÁRIA DO TRIÂNGULO MINEIRO BALANÇO PATRIMONIAL}

EM_l_ ${ }^{\prime}$

ATIVO

\begin{tabular}{|c|c|c|}
\hline & $19 \times 2$ & $19 \times 1$ \\
\hline ATIVO CIRCL & & \\
\hline ATIVO REALI & & \\
\hline ATIVO PERM & & \\
\hline INVESTIMEN & & \\
\hline IMOBILIZADC & & \\
\hline OPERACION & & \\
\hline (-) Depreciaçã & & \\
\hline SOCIAL & & \\
\hline Prédio Escola & & \\
\hline Biblioteca & & \\
\hline Salas para $\mathrm{Pa}$ & & \\
\hline Veículos Assi & & \\
\hline Equipamentos & & \\
\hline Etc. & & \\
\hline (-) Depreciaçã & & \\
\hline DIFERIDO & & \\
\hline Total do Ativo & & \\
\hline
\end{tabular}

PASSIVO

\begin{tabular}{|l|l|l|}
\hline & $19 \times 2$ & $19 \times 1$ \\
\hline PASSIVO CIRCULÂNTE & & \\
\hline EXIGÍVEL EM LONGO PRAZO & & \\
\hline RESULTADO DE EXERCÍCIOS FUTUROS & & \\
\hline Capital Social & & \\
\hline
\end{tabular}

Caderno de Estudos nº10, São Paulo, FIPECAFI, Maio/1994 


\begin{tabular}{|l|l|l|}
\hline & & \\
\hline Reserva de desenvolvimento & & \\
\hline Reserva Assist. Téc. Educ. e Social RATES & & \\
\hline Fundo Assist.Téc. Educ.e Social FATES & & \\
\hline Retorno "Pro-Rata" & & \\
\hline & & \\
\hline Total Passivo & & \\
\hline
\end{tabular}

Como pode ser observado, estamos indicando apenas algumas alterações em sua estrutura, para que, além da representação da posição patrimonial voltada para a condição de organização econômica, fosse dada ênfase também à sua condição de organização social. Estamos primeiramente propondo a segregação do Ativo Imobilizado Permanente em:

a) Ativo Permanente Imobilizado Operacional e,

b) Ativo Permanente Imobilizado Social.

O imobilizado Operacional teria como função representar os bens destinados à manutenção das atividades operacionais da cooperativa de uma forma geral, em sua condição de organização econômica; o Imobilizado Social representaria única e exclusivamente a manutenção dos bens destinados à sua função social.

Por outro lado, estamos propondo também a segregação na conta reserva no grupo do Patrimônio Líquido, que terá como objetivo principal canalizar as origens dos recursos originários de suas sobras e destinados a suprir as verbas direcionadas à sua função social; seria assim demonstrado:

a) Reserva de Assistência Técnica, Educacional e Social - RATES

b) Fundo de Assistência Técnica, Educacional e Social -FATES.

A RATES demonstraria o saldo de recursos sociais a aplicar e a FATES, o saldo de recursos já aplicados. a FATES teria também como objetivo, além de controlar os bens aplicados em Ativo Fixo, oferecer condições de conhecermos as Despesas Sociais ocorridas no período considerado

O Balanço Patrimonial, por nós idealizados para as Sociedades Cooperativas, de uma forma simplificada, estaria assim representado:

\begin{tabular}{|l|l|}
\hline \multicolumn{2}{|c|}{ BALANÇO PATRIMONIAL } \\
\hline ATIVO & PASSIVO \\
\hline ATIVO CIRCULANTE & PASSIVO CIRCULANTE \\
\hline REALIZAVÉL EM LONGE PRAZO & RESULTADO EXERC. FUTUROS \\
\hline ATIVO PERMANENTE & \\
\hline INVESTIMENTOS & \\
\hline IMOBILIZADO & \\
\hline
\end{tabular}

Caderno de Estudos nº10, São Paulo, FIPECAFI, Maio/1994 
Contribuição a Análise e Estruturação das Demonstrações Financeiras das Sociedades 8 Cooperativas Brasileiras

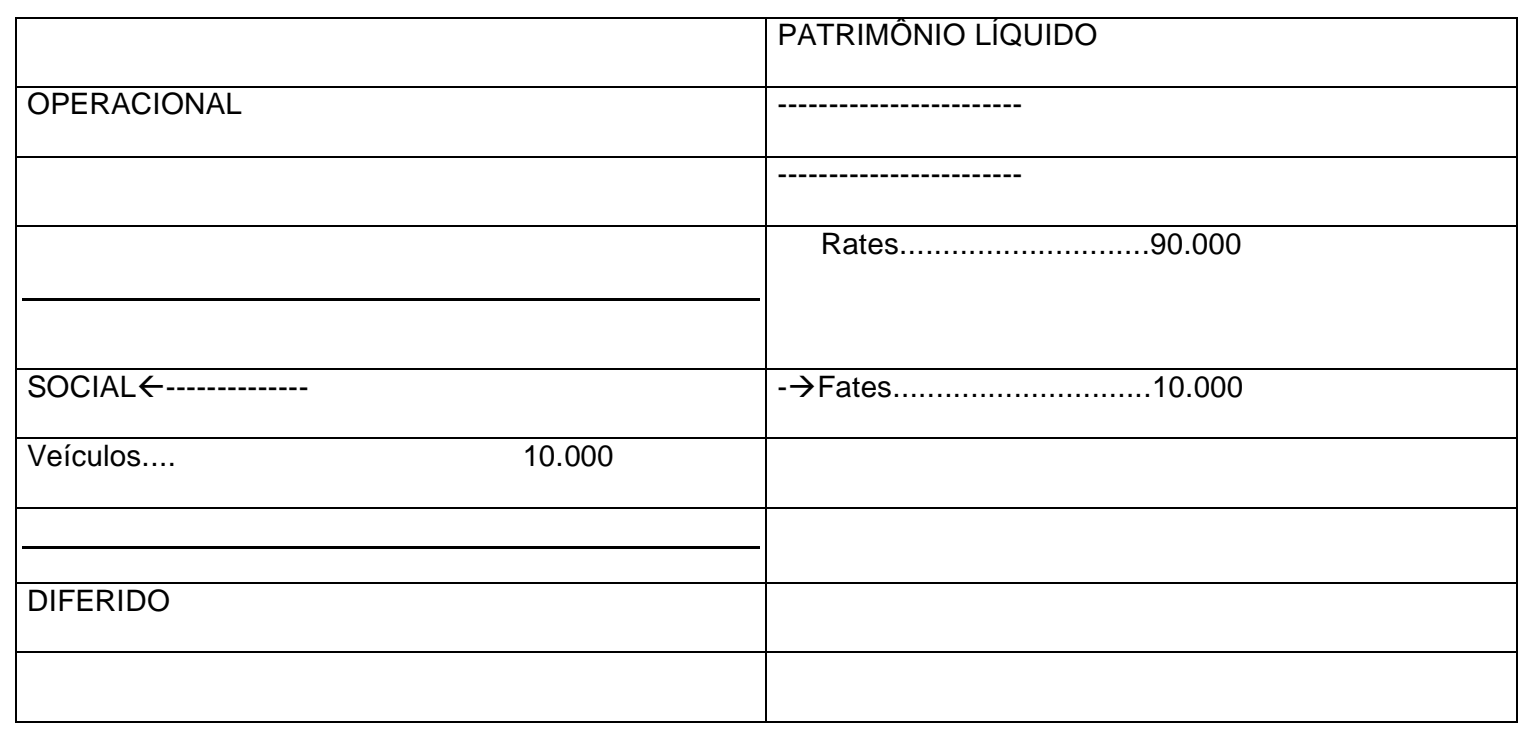

Obs. Valores aleatórios, de caráter exemplificativo.

Estamos admitindo, aqui, a movimentação segregada na conta FATES, como uma verdadeira "Contabilidade por Fundos", indicada principalmente para as entidades de natureza ou finalidade não lucrativa, como é o caso das Cooperativas Entendemos que o saldo da conta FATES representa recursos de uso restrito e disciplinado, que estariam aplicados, em contra-partida, no Ativo Permanente Imobilizado Social.

Com a finalidade de informar em cada exercício social, ou em cada período considerado, a movimentação de operações de cooperativa em seu aspecto Social, sugerimos a "Demonstração de Movimentação do FATES", conforme modelos por nós idealizado e demonstrado a seguir:

\begin{tabular}{|l|l|l|}
\hline \multicolumn{1}{|c|}{$\begin{array}{c}\text { COOPERATIVA AGROPECUÁRIA DO TRIÂNGULO MINEIRO } \\
\text { DEMONSTRAÇÃO DE MOVIMENTAÇÃO DO FATES - DMF } \\
\text { PERIODO : 01.01.X1 A 31.12.X1 }\end{array}$} \\
\hline & \multicolumn{1}{|c|}{ Saldo em 31.12.X0 } & \\
\hline$(+)$ & Resultado da Correção Monetária & 15.000 \\
\hline$(+)$ & Transferência da Conta RATES no Exercício & \\
\hline$(-)$ & Aplicação em Despesas Sociais no Exerc. 19X1 & 5.000 \\
\hline & DESPESAS SOCIAIS & \\
\hline & .Salário e Ordenados & 5.000 \\
\hline & .Encargos Sociais & \\
\hline & .Desp.c/ Assistência Técnica & \\
\hline & .Desp. com Cursos e Palestras & \\
\hline & . Despesas com veículos & \\
\hline
\end{tabular}

Caderno de Estudos nº10, São Paulo, FIPECAFI, Maio/1994 


\begin{tabular}{|l|l|l|}
\hline & $\mid$ & \\
\hline & .despesas com Creches & \\
\hline & . Despesas com Combustíveis & \\
\hline & . Despesas de Depreciação & \\
\hline & & \\
\hline$(=)$ & Saldo em 31.12.X1 & 10.000 \\
\hline & & \\
\hline & & \\
\hline
\end{tabular}

\begin{tabular}{|c|c|c|}
\hline \multicolumn{3}{|c|}{$\begin{array}{c}\text { Aplicação no Imobilizado Social } \\
\text { Imobilizado Social }\end{array}$} \\
\hline & Prédio Escolar & \\
\hline & Biblioteca & \\
\hline & Equipamentos para Laboratório & \\
\hline & Veículos & 10.000 \\
\hline$(+)$ & Depreciação Acumulada & \\
\hline & Total Aplicado e Imobilizado Social & 10.000 \\
\hline
\end{tabular}

Obs: Valores aleatórios, de caráter exemplificativo.

Este demonstrativo, conforme pode ser observado no modelo proposto, mostrará o saldo da conta FATES no início do exercício, o total dos recursos transferidos da conta RATES, bem como demonstrará toda a sua movimentação durante o período considerado, tanto nas aplicações em contas de Resultado em suas Despesas Sociais, bem como os Investimentos Fixos realizados em seu Imobilizado social

Elaboramos o demonstrativo em dois módulos para facilitar a sua interpretação por parte do usuário tanto interna como externamente.

Em primeiro plano, teríamos a demonstração das Despesas Sacias, que, pelas suas características de contas de Resultado, estariam deduzindo de fato o saldo da conta FATES, uma vez que elas representam gastos de manutenção das atividades sociais. A conta FATES representaria urna conta de controle dos gastos sociais funcionaria como conta transitória na contra-partida para encerramento das despesas sociais no final de cada exercício.

Acompanhando a Demonstração de Movimentação do FATES, deverão também ser elaboradas em forma de "anexos", os relatórios estatísticos e descritos em toda a atividade social da cooperativa, desenvolvida durante o exercício social.

Este relatório, idealizado por nós, pode ser considerado como genuinamente aplicado ao setor cooperativista, uma vez que terá a meta principal de demonstrar essa outra dimensão do cooperativismo, ou seja, o seu lado social, que é totalmente relegado em segundo plano nas Demonstrações Financeiras elaboradas atualmente pelas Sociedades Cooperativas. A grande maioria delas nem mesmo faz menção da existência dessa característica, desprezando a orientação doutrinária existente já há quase dois séculos. A ênfase atual é voltada quase que totalmente para o seu aspecto econômico,

Entendemos, em nosso ponto de vista, que a Sociedade Cooperativa tem quase que obrigação de mostrar aos seus associados, ao governo, e até mesmo à comunidade onde está instalada a sua contribuição de caráter social, considerando a sua condição de entidade sem fins lucrativos.

Tanto para elaborarmos o Balanço Patrimonial como a Demonstração de Movimentação do FATES, conforme nossa proposição. teremos inicialmente que considerar a segregação no Plano de Contas da cooperativa, para em seguida analisar as implicações pertinentes.

De uma forma simplificada, podemos imaginar aqui um plano de Contas para uma cooperativa, com ênfase na segregação do Ativo Permanente e nas Reservas (RATES e FATES) também haverá necessidade de

Caderno de Estudos nº10, São Paulo, FIPECAFI, Maio/1994 
Contribuição a Análise e Estruturação das Demonstrações Financeiras das Sociedades 10 Cooperativas Brasileiras

segregação das despesas sociais na composição das Contas de Resultado, conforme indicamos a seguir:

PLANO DE CONTAS

(Simplificado)

\section{ATIVO}

1.1. Circulante

1.2. Realizável à Longo Prazo

1.3. Permanente

1.3.1. Investimentos

1.3.2. Imobilizado

1.3.2.1. Operacional

1.3.2.2. Social

1.3.3. Diferido

\section{PASSIVO}

2.1. Circulante

2.2. Exigível à Longo Prazo

1.3. Resultado de Exercícios Futuros

\section{PATRIMÔNIO LÍQUIDO}

3.1. Capital Social

3.2. Reserva Legal

3.3. Reserva para Desenvolvimento

3.4. Reserva de Assistência Técnica, Educacional e Social -RATES

3.5. Fundo de Assistência Técnica, Educacional e Social -FATES

3.6. Retorno "Pro-Rata"

\section{VENDAS BRUTAS}

\section{DESPESAS OPERACIONAIS}

5.1. Despesas Administrativas

5.2. Despesas com Vendas

5.3. Despesas Financeiras (Líquidas)

5.4. Despesas Sociais

A composição do Ativo Permanente Imobilizado com a segregação idealizada, seria a seguinte:

\subsubsection{IMOBILIZADO}

\subsubsection{Operacional}

132.1.1. Imóveis

1.3.2.1.2. Veículos

Caderno de Estudos nº10, São Paulo, FIPECAFI, Maio/1994 
Contribuição a Análise e Estruturação das Demonstrações Financeiras das Sociedades 11 Cooperativas Brasileiras

1.3.2.1.3. Moveis e Utensílios

1321.9 (-) Depreciação Acumulada

\subsubsection{Social}

13 2.2.1. Imóveis

1.3.22.2 Veículos

1.3.2.23 Móveis e Utensílios

1.3.2.2.4

1.3.2.2.9 (-) Depreciação Acumulada

No grupo do Patrimônio Líquido teríamos as Contas de Reserva de Assistência Técnica, Educacional e Social - RATES e Fundo de Assistência Técnica, Educacional e Social - FATES. Essas duas contas representariam a origem de recursos com finalidade de aplicação social, sendo que a primeira (RATES) representaria o saldo de recursos a aplicar e, a segunda (FATES) representaria o saldo de recursos já aplicados pela cooperativa.

No caso das despesas sociais, teríamos de uma forma exemplificada, o detalhamento das seguintes contas:

\section{4. DESPESAS SOCIAIS}

$\begin{array}{lc}\text { 5.4.1. } & \text { Salários e Ordenados } \\ 5.4 .2 . & \text { Encargos Sociais } \\ 543 & \text { Despesas com Assistência Técnica } \\ 5.4 .4 & \text { Despesas com Cursos e Palestras } \\ 5.4 .5 & \text { Despesas com Veículos } \\ 5.4 .6 & \text { Despesas com Creches } \\ 5.4 .7 & \text { Despesas com Refeitórios } \\ 5.4 .8 & \end{array}$

As despesas sociais deveriam ainda ser segregadas por departamento, de acordo com o Organograma existente na Cooperativa, tais como: Departamento Médico, Departamento Odontológico, Departamento Veterinário, Departamento Jurídico etc.

Ainda para melhor apresentação das Demonstrações Financeiras das Sociedades Cooperativas, lembramos da importância da aplicação da técnica da Correção Integral, conforme preconiza a Instrução Normativa $n^{0} 64$ da Comissão de Valores Mobiliários - CVM, de 19.05.1987, bem como suas posteriores alterações, no sentido de possibilitar, aos seus usuários, uma compreensão mais adequada de sua situação patrimonial e financeira.

\section{7) Conclusão}

O presente trabalho permitiu apresentarmos as seguintes propostas e sugestões:

- Adaptações em algumas Demonstrações já existentes e propostas de novas Demonstrações Financeiras específicas para as Sociedades Cooperativas. Tanto as adaptações aos modelos existentes como a proposição de novos modelos, visaram, principalmente, a demonstrar que, além de sua condição de entidade econômica, as cooperativas devem apresentar dados que permitam, aos seus usuários verificar,

Caderno de Estudos nº10, São Paulo, FIPECAFI, Maio/1994 
Contribuição a Análise e Estruturação das Demonstrações Financeiras das Sociedades 12 Cooperativas Brasileiras

em determinado período considerado, as realizações de suas atividades sociais - as quais, em nosso ponto de vista, são uma das principais razões da existência da cooperativa, entidade sem fins lucrativos.

- Para atingir essa finalidade, sugerimos que o Ativo Permanente, constante no Balanço Patrimonial das Sociedades Cooperativas, seja segregado em: Ativo Permanente Imobilizado Operacional e Ativo Permanente Imobilizado Social. Sugerimos também a segregação em duas contas de Patrimônio Líquido para demonstrar a origem dos recursos de finalidades sociais. Em nossa proposta, a conta Reserva de Assistência Técnica, Educacional e Social -RATES demonstrará o saldo de recursos sociais a aplicar e a conta Fundo de Assistência Técnica, Educacional e Social -FATES demonstrará os recursos sociais aplicados. Esta última conta representará, contabilmente, uma conta de controle que mostrará os montantes aplicados, tanto em investimentos em ativo fixo, quanto em despesas sociais de cada período contábil considerado.

- Para operacionalizar nossa proposta, sugerimos as respectivas adaptações dos Planos de Contas, nos tópicos específicos necessários ao desenvolvimento de nosso trabalho. Entretanto, esclarecemos que os mesmos merecem um estudo mais completo e abrangente, para que as cooperativas utilizem-no de forma homogênea e padronizada em nosso país.

- Com o objetivo de demonstrar os recursos aplicados nas atividades sociais das cooperativas, sugerimos a elaboração da Demonstração de Movimentação do FATES, com fins específicos para as Sociedades Cooperativas. Deste modo, ficam evidenciados os gastos em despesas e investimentos sociais, itens que as Demonstrações Financeiras atuais não destacam.

Este trabalho é uma tentativa de contribuição à Contabilidade das Sociedades Cooperativas, com o objetivo básico de sugerir a elaboração de demonstrações Financeiras que possam refletir a posição do Movimento Cooperativista Brasileiro, com seus princípios doutrinários e normas específicas. Visa a demonstrar também, de uma maneira clara e objetiva, aos associados de cooperativas, ao governo e à própria sociedade, a contribuição dos aspectos sociais da empresa cooperativista como entidade sem fins lucrativos.

Caderno de Estudos nº10, São Paulo, FIPECAFI, Maio/1994 
Contribuição a Análise e Estruturação das Demonstrações Financeiras das Sociedades 13 Cooperativas Brasileiras

BIBLIOGRAFIA

Anuário do Cooperativismo Brasileiro - Brasília, OCB, 1991.

CARNEIRO, Palmyos P. - Cooperativismo - O princípio cooperativo e força existencial-social do trabalho - Belo Horizonte, FUNDEC 1981.

Lei 5764 , de 16 de dezembro de 1971.

PECAR, Samuel - Manual de Contabilidade de Cooperativas Agropecuárias - Israel, Centre de Estudos Cooperativos y Laboriales, 1981.

PEREIRA, Anísio Candido - Contribuição á Análise e Estruturação das demonstrações Financeiras das Sociedades Cooperativas Brasileiras - Ensaio de Abordagem Social - Tese de Doutoramento, São Paulo, FEA/USP, 1993.

PINHO, Carlos Marques et. al. - As Grandes Coordenadas da Memória do Cooperativismo Brasileiro - Vol. I Brasília, OCB, 1991.

PINHO, Diva Benavides - A Doutrina Cooperativa nos Regimes Capitalistas e Socialistas - São Paulo, Livraria Pioneira Editora, 1966.

Economia e Cooperativismo, São Paulo, Ed. Saraiva, 1977.

O Pensamento Cooperativismo e o Cooperativismo Brasileiro

Manual de Cooperativismo, - Vol. I, São Paulo, CNPQ, 1982.

TAKAHASHI, Minoru - Análise da Administração Contábil das Cooperativas Agrícolas do Estado do Paraná Dissertação de Mestrado, Belo Horizonte, Universidade Federal de Minas Gerais, 1982. 